\title{
Agent-Based Simulation Research on Urban Land Development of San Diego
}

\author{
Runjiao Liu \\ The Architectural and Art school of Central South University, Changsha, Hunan, China \\ Email: 471285954@qq.com
}

How to cite this paper: Liu, R. J. (2020). Agent-Based Simulation Research on Urban Land Development of San Diego. Current Urban Studies, 8, 658-687. https://doi.org/10.4236/cus.2020.84036

Received: December 17, 2020

Accepted: December 26, 2020

Published: December 29, 2020

Copyright (c) 2020 by author(s) and Scientific Research Publishing Inc. This work is licensed under the Creative Commons Attribution International License (CC BY 4.0).

http://creativecommons.org/licenses/by/4.0/

(c) (i) Open Access

\begin{abstract}
This paper introduces an individual-based simulation model to study the land development process in San Diego by using multi-agent simulation (MAS) software, where the urban expansion activities are realized through the construction behaviors of three major types of developer agents (residential/industrial/commercial). Except compiling codes for the interaction activities between different kinds of agents and their surrounding environment, this model also includes the analysis function of urban renewal into the simulation process. And in order to find a suitable land policy for urban growth management in San Diego, this paper conducts a prediction research about future land development in three different types of administration scenarios, and evaluates their simulation layouts from two separate perspectives: visual observation and geometrical calculation. After that, following the suggestions of comprehensive plan in 2050 and smart growth principles, this paper proposes a series of measures for the improvement of current land management, and verifies their effectiveness through the comparison research between optimized scenario and other three administration policies mentioned above. Also, for the purpose of increasing simulation layout's consistency with the real world, several possible ways are put forward to optimize the modeling procedures at the end of this paper.
\end{abstract}

\section{Keywords}

Multi-Agent System, Agent, Urban Land Use, Bottom-Up, Urban Expansion, Urban Renovation

\section{Introduction}

Over the past few decades, the major cities in the world, especially those developing countries have gone through a radical change in both physical and social 
economic conditions, of which the most impressive is the urban expansion with an unprecedented speed (Mansury, 2015; Ronghui et al., 2015). According to the reports of World Urbanization Prospects (2014), the proportion of urban population is expected to reach $67 \%$ by the year 2050 , which can provide the social economic development with great impetus. But due to limited land resources, such a huge construction need will not only exacerbate the existing conflicts between nature preservation and urban development, but also bring about negative impacts on maintaining the ecological balance and setting up a healthy living environment for urban dwellers. In considering of this matter, how to predict the quantity and spatial distribution trend accurately for urban land development has become one of the most important issues in related research areas; and only if the government can draw up reasonable as well as practical management policies based on the projection results, can urban system ensure people with a sustainable development mode in the future.

Given the fact that the urban system is evolved with economic growth, political reform and many other social or physical development activities, the space distribution structure of urban land use and its forming process will display the characteristics of dynamics and complexity on account of the close interactive relationships among different sub-systems (Parker \& Filatova, 2008). So, the traditional "top-down" modeling methods which set up simulation research with static, homogeneous environment assumptions cannot fully represent those mutual influences brought by individual activities (Benenson, 1998; Runjiao et al., 2016). Therefore, it may cause relatively higher deviations when researchers are trying to use it to explain the internal operation mechanisms or to predict the future development situations for urban land system. Fortunately, the emergence of complex theory and agent-based simulation software has shed some new lights on the improvements of land transformation research (Batty, 2005; Heppenstall et al., 2012). Because its "bottom-up" modeling structure together with the individual-based research method can provide a more scientific and realistic way to explore the underlying interrelationships between micro individual activities and macro space patterns, through enabling us to simulate both information and material exchanges among different components and at multiple levels in one single model (Benenson, 1998; Honghui, 2011; Railsback \& Grimm, 2012; Runjiao et al., 2016). As a result, for the purpose of verifying the effectiveness of $\mathrm{ABM}$ (Agent-base Model) technology in urban system research, this paper will use ABM software to build up a simulation model for San Diego's land development and organize its research process as follows: firstly, it will come up with a detailed design of modeling structure and agents' behavior rules after summarizing the research experiences of previous studies; then, it will apply this model to simulating the land expansion activities as well as urban renewal process from 2008 to 2014; after that, it will compare the differences between simulation layout and actual land use pattern through both observation and calculation approach; as the accuracy of this modeling research has been ve- 
rified, it will continue to predict the land development trend for 2050 in three different simulation scenarios and set up an ideal planning strategy based on their comparison results; when coming to the end of this paper, it will not only conclude with a general discussion on model achievements and its limitations, but also propose several possible guidelines for the improvements of future research.

\section{Literature Review}

As described in previous research, the main function mechanism for $A B M$ is to set up virtual agent to represent individuals or organizations in real world, and make them interact with each other through various activities like competing, cooperating decision-making and so on. The model environment would slightly change every time these agents take actions, and when they accumulate to a certain degree, some particular patterns from the macro-level would emerge unpredictably and bring influences to the future behaviors of agents consequently, as shown in Figure 1. Compared to the traditional modeling methods, there are several advantages for applying $\mathrm{ABM}$ techniques in urban land simulation research, which include (Arsanjani et al., 2013; Crooks, 2006; Marks, 2006; Matthews et al., 2007; Parker et al., 2003; Ronghui et al., 2015; Verburg, 2006): 1) it can represent multiple kinds of characteristics and behavior rules in one single model; 2) all agents can act independently without following the instructions of central institution; 3 ) it is easier to collect data for setting up local behavior rules in micro-level; 4) the "bounded rationality " can be realized through limiting the agent's perception area.

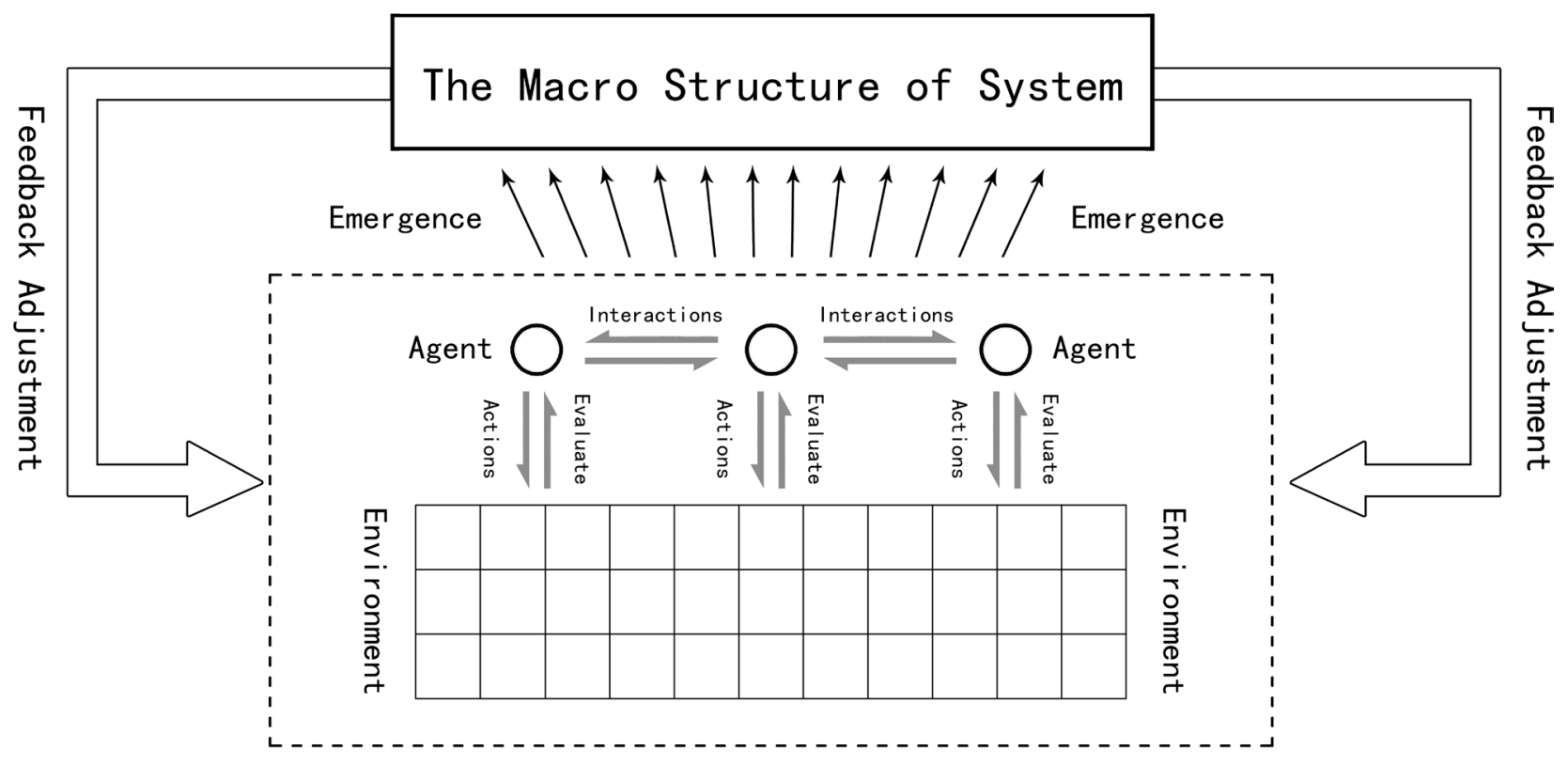

The Micro Activities of Agents

Figure 1. The operation mechanism in agent-based model. 
Through the literature reviewing process, it is easy for us to see that most agent-based simulation research of urban land use are conducted from the market competing perspective, which means all kinds of agents, no matter residents, government or developers, would make their decisions based on the calculation results between revenues and costs.

Filatova, Parker and Veen (2009) are one of pioneers who combine the principles of microeconomics into the simulation process of urban land change and its transactions. And they have done a detailed research on the discrete, bilateral trading behaviors between buyers and sellers, in which the land transaction price will be determined by both the willingness to pay and the willingness to sell. Furthermore, in order to study the change rule of land price, they also set up several comparison research by adjusting the land market into different supply situations.

When Ettema (2011) conduct research on residential land change through housing transactions, they assume that both the willingness to move and the price formation process will be influenced by the individual's perception on housing market as well as their preferences and financial budgets. Except that, they also innovatively design a price-updating mechanism with the Bayes formula so that they could more clearly represent the dynamic characteristics of price negotiation behaviors.

As to the research of Magliocca, Safirova, Mcconnell and Walls (2011), they improve the simulation structure not only by building a heterogeneous modeling environment, but also by adding random factors as well as path-dependence mechanism into agent's decision-making process. And for the purpose of distinguishing the influences of land price from housing transactions, they also design two separate modeling procedures for each one of them, and follow their respective development requirements and evaluation standards to set up agent's behavior rules.

After that, Sun, Parker, Huang, Filatova and Brown (2014) establish a similar land development research with a relatively simplified modeling environment, and use it to explore the performances of land market in different simulation scenarios. By comparing the fragmentation index, the quantity of converted lands and other space indicators among those experiments, they also prove the fact that how to set up the financial budget and the competitive mechanism could play a vital role in determining the accuracy of simulation results, so researchers should pay a lot of attention when handling these two factors.

In recent study, many modelers begin to combine other analysis techniques to optimize the traditional ABM research. For example, Ronghui et al. (2015) not only take the advantage of the lattice transition rule in cellular automata to set up the virtual environment, but also use the game theory to improve the decision-making process for land market, which enables the government agents to find a more effective as well as profitable solution among different kinds of competition scenarios by setting up the game tree for all potential development 
choices.

As to the optimization work done by Zhuge and his colleagues (Zhuge et al., 2016), it mainly focuses on adding different analysis functions, like transportation design and travel forecasting into the simulation model when following the instructions of utility maximization and prospect theory. Besides that, it also tries to innovatively build a dynamic price negotiation mechanism between sellers and buyers, and increase the accuracy of experiment by using the genetic algorithm to evaluate parameter values for the simulation program.

Although those case studies mentioned above show us that the current ABM research has obtained great achievements in representing the complex characteristics of urban land system and exploring the interactive operation mechanism of micro agents, it still has some drawbacks that could prevent it from being applied into more extensive studies. Thereinto, the simulation structure dominated by transaction behavior and residential land development has greatly limit its use in general urban land research, especially the overall prediction. Because this kind of model lacks the ability to describe the urban transition process of other land use type, like the vacant or developed land, which is mainly determined by the government administration not by land market. And the omission of some important development activities, like the allocation of public service and infrastructure facilities, could also cause severe deviation in its final simulation results, due to the fact that the mutual influences among different urban land use may sometimes play a more important than market profits in resident's decision-making process, just like people do in the NIMBY phenomenon. Therefore, in order to explore the internal operation mechanism for urban land system in San Diego and to make accurate predictions about its future development trend, this simulation research will choose three most important land use types (residential, industrial and commercial) (Robinson et al., 2012) as its research targets and design modeling behavior rules for each one of them separately, so that it could conduct research on future land development through different kinds of interactive activities among agents and their surrounding environment.

\section{Model Description}

\subsection{Study Area}

The research area (the city of San Diego) is located in the Pacific coastal region of southwest America, near the Mexico border. Due to its favorable weather conditions and abundant natural resources, both the tourism and the agriculture production have been well developed. Meanwhile, the long time history of being chosen as navy bases and the great efforts of constructing educational facilities and research centers, also provide a powerful driver for industrial development. Plus the convenient transportation location could facilitate the foreign transactions to a great extent, San Diego has a relatively diverse and prosperous economy compared to other cities with similar conditions, which leads to an increas- 
ing demand of construction land accordingly. But after being affected by its rough mountain topography, the strict protection policies of ecological environment and the distribution of military facilities, there is not too much room left for the urban expansion activities. Therefore, San Diego has a severe problem in balancing the construction needs and environment protection, and how to find a suitable land development scheme that could address both of them adequately through the modeling process would become the primary task of this simulation research.

\subsection{Simulation Structure}

According to different conversion sources, the land development activities in this model could be divided into two main types: urban expansion and urban renewal. As indicated by their names, urban expansion refers to the land transition process from non-city area into the residential, industrial or other urban land use types, while the urban renewal mainly focuses on the updating activities of developed land inside the build-up area, like the industrial rehabilitation. Although the second one is barely studied by previous land simulation research, considering the fact that the quantity of industrial land in San Diego has been dropped obviously since 2008 and most of them are caused by industrial renewal projects, it is necessary for us to include this type of land conversion process into the modeling procedure. Otherwise, the misrepresenting of industrial land development would not only cause deviations in predicting the future expansion trend for industrial land itself, but also bring negative effects to the allocation process of both residential and commercial land, which is highly influenced by the spatial position of industrial facilities. So, for the purpose of ensuring the accuracy of simulation results, this model would combine urban expansion and urban renewal together into the modeling process so as to increase its fitting degree with the real world as much as possible.

As shown in Figure 2, the whole simulation program consists of five independent modeling functions. To begin with the research, the simulation software (NetLogo) has to import all kinds of graphic files and statistic data from outer documents in "data preparation" stage, and assign those attribute values into different corresponding procedures. Then, the simulation model would gather information about the current modeling time and the total area of different land use types (residential, industrial and commercial land), and use them to determine the land transition tasks that should be done in this cycle (year) for both urban renewal and urban expansion activities. After that, the simulation procedure would come into the stage of "urban renewal", where the government agent is in charge of picking out the suitable industrial land for rehabilitation, and both residential and commercial developer agents would compete with each other to develop that land parcel following the procedures of "urban expansion".

It is worth noting that those transition activities in urban renewal stage could cause a great change in the total area of residential or commercial land, so these 


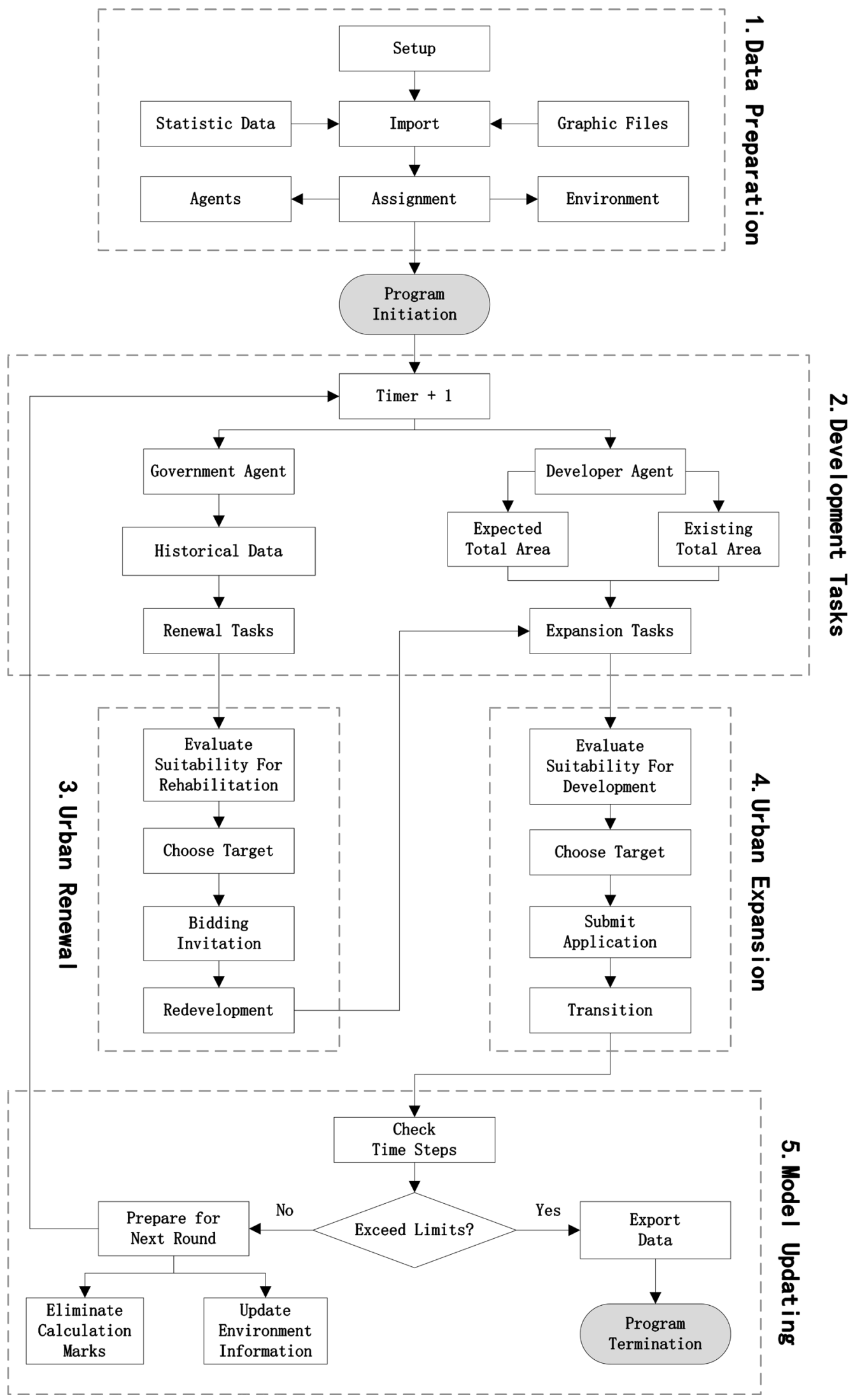

Figure 2. The flow chart of land development simulation process. 
developer agents should recalculate their expansion tasks after the renewal procedure has come to an end. As a result, in order to simplify the calculation process, the simulation program would not only put the urban renewal function in front of the execution sequence, but also stipulate that only after the rehabilitation job has been done, can urban expansion procedure begins to work. For the simulation activities in "urban expansion" stage, all developer agents would firstly follow the same evaluation procedures but with different parameter values to choose their own target lands, and then submit their transition applications to the government agent and wait for its judgment. After receiving a positive answer from the government agent, they would convert the target land into the same land use type as their own. And when the developer agents finish all of expansion tasks, the simulation program would launch the "model updating" procedures to check whether the simulation time has exceeded its maximum limit. If it doesn't, the modeling procedure would start the next round experiment after eliminating the current calculation marks and updating the city environment. Otherwise, the modeling procedure would export the images of urban space layout together with some other statistic data, and then terminate the whole simulation program.

\subsection{Behavior Rules}

\subsubsection{Developer Agent}

As mentioned above, all three types of developer agents, which include residential, industrial and commercial, will follow the same modeling procedures to finish their expansion tasks. Therefore, they would firstly choose the target land based on their own development preferences, and then apply for the construction permission from the government. After receiving the positive answer, the developer agents would take the converting actions on target land parcels, and check the environment information to determine whether they should continue their expansion job in the end of these modeling procedures. More specific details about how developer agents evaluate and make decisions during the expansion stage can be seen in the following paragraphs and Figure 3.

1) Calculating Expansion Tasks

In order to make sure that the quantity of converted land is always consistent with the requirements during the dynamic simulation process, the calculation procedure for developer agents would be divided into two separate parts: the total area projection and the task calculation. Agents would firstly use the linear regression formula (Formula (1)) to forecast the total area that each land use type should reach at the beginning of this round (year) simulation research, and then follow the descriptions of Formula (2)) to calculate the remaining expansion task whenever they want based on the statistic data of current land distributions.

$$
\begin{gathered}
A_{x 1}=\alpha_{x} \times\left(t+t_{0}\right)+\beta_{x} \\
A_{x}=A_{x 1}-A_{x 0}
\end{gathered}
$$




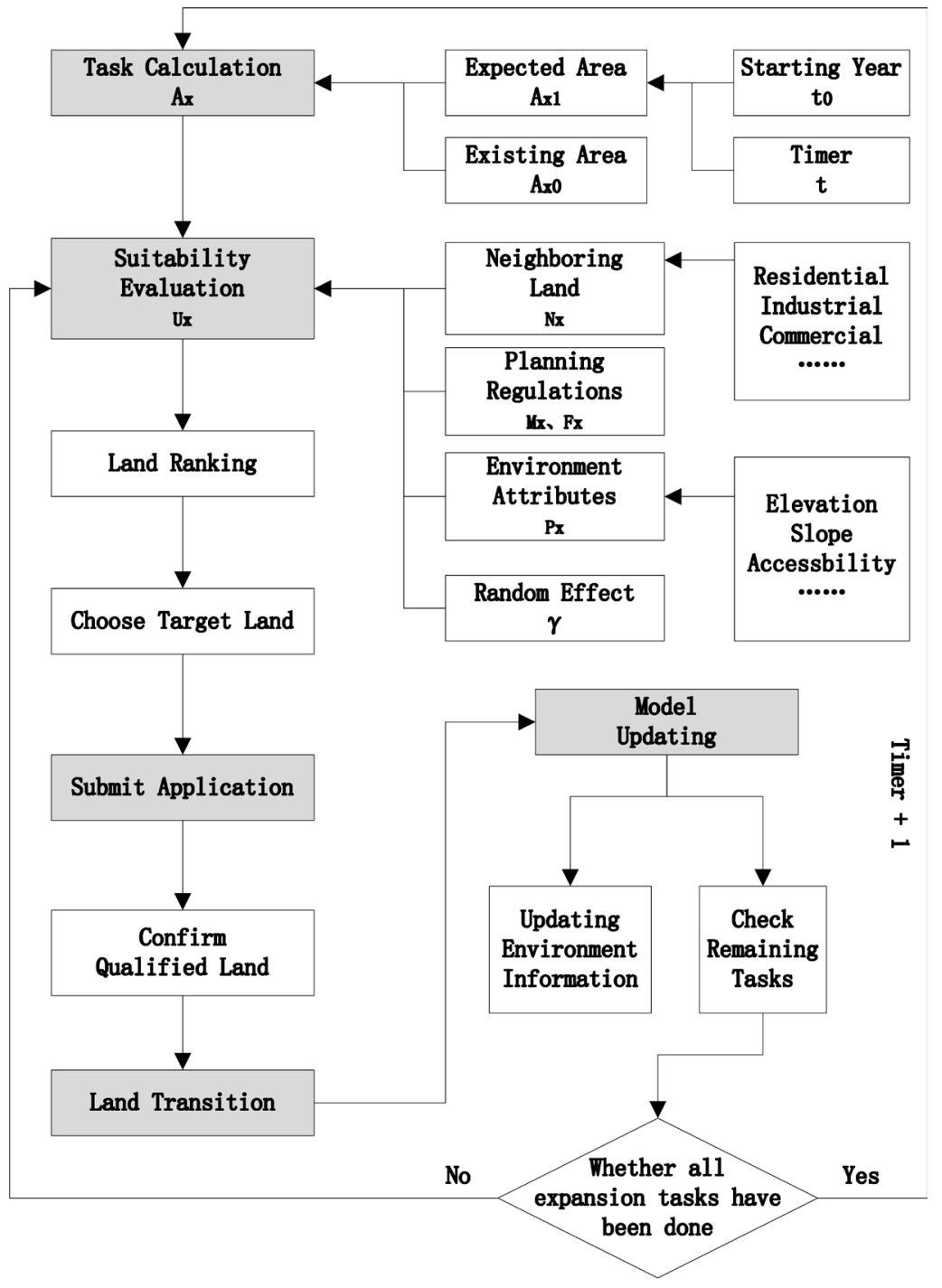

Figure 3. The flow chart of urban expansion process.

In Formulas (1)-(2), $x$ represents the land use type of developer agent, which includes three kinds of choices: $r$ (residential), $i$ (industrial) and $c$ (commercial); $\alpha_{x}$ and $\beta_{x}$ are the slope coefficient and the intercept coefficient for linear regression formula; $t$ is the time steps of current simulation program, and its unit time equals one year in real world; $t_{0}$ is the baseline year where simulation research begins to analyze.

2) Evaluating Suitability for Undeveloped Land

According to previous studies, there are three types of factors that could place great influence on the decision-making process of developer agents, and they are "environment attributes", "planning regulations" and "neighboring land" respectively (Haase et al., 2012; Honghui, 2011; Yali, 2013). Therefore, when developer agents compare different land choices to identify the most suitable one, they have to evaluate the performances of those three factors separately (as shown in Formulas (3)-(6)), and then use Formula (8) to calculate the synthe- 
sized suitability value (Xia, 2003) for all potential land parcels.

a) The evaluation of environment attributes

$$
P_{x}=w_{\text {zh-elev }} S_{\text {elev }}^{\prime}+w_{\text {zh-slope }} S_{\text {slope }}^{\prime}+w_{\text {zh-green }} S_{\text {green }}^{\prime}+\cdots+w_{\text {zh-mf }} S_{m f}^{\prime}
$$

In Formula (3), $x$ represents the land use type of developer agent, which includes three kinds of choices: $r$ (residential), $i$ (industrial) and $c$ (commercial); $P_{X}$ is the synthesized evaluation result of all attribute factors; $S_{\text {elev }}^{\prime}, S_{\text {slope }}^{\prime}, \cdots$ are the environment attribute factors that developer agents concern most, and before being applied into the calculation process, they have to go through a series of transition procedures to avoid analysis bias, as shown in Appendix $1 ; \omega_{\text {zh-elev }}, \omega_{\text {zh-slope }}, \cdots$ are the weight coefficients corresponding to different attribute factors, and their calculation details can been in Appendix 1.

b) The evaluation of neighboring land

$$
N_{x}=\left(\sum_{x-m}(\text { Landuse }=\text { “ } x ")\right) / n
$$

In Formula (4), $N_{x}$ represents the evaluation results of land use type $x$ within a limited area around the target parcel; $x$ - $m$ is the search radius that developer agents use to limit the scope of assessment; and $n$ is the total area of land parcels within the range of $x$ - $m$, while $\sum$ (Landuse $=$ " $x$ ") represents the total area of land parcels with the particular land use type of $x$.

c) The evaluation of planning regulations

$$
\begin{gathered}
M_{x}=\left\{\begin{array}{lc}
1 & \text { Allowed to build (If } D M_{x}>R M_{x} \\
0 & \text { Not allowed to build (If } D M_{x} \leq R M_{x}
\end{array}\right) \\
F_{x}=\left\{\begin{array}{lc}
1 & \text { Allowed to build (If } D F_{x}>R F_{x} \\
0 & \text { Not allowed to build (If } D F_{x} \leq R F_{x}
\end{array}\right)
\end{gathered}
$$

In Formulas (7)-(8), both $M_{x}$ and $F_{x}$ are used to evaluate the suitability between land use type $x$ and certain restriction rules, among which $M_{X}$ is the evaluation result of military restrictions while $F_{X}$ is the result of industrial restrictions; as to $D M_{x}$ and $D F_{x}$, they are representing the space distance from target land parcel to its nearest military stations or industrial facilities; $R M_{X}$ and $R F_{X}$ are the restriction radius used to identify the non-construction zones around those military or industrial lands. Also, considering that the industrial land development also need to obey the restriction rules to keep certain distance away from the residential or commercial facilities, it will adopt a different way to calculate the suitability values for industrial restrictions, as shown in Appendix 2.

d) The calculation of synthesized suitability value

$$
\begin{gathered}
\text { Random }=\left(1+(-\ln \gamma)^{\partial}\right) \\
U_{x}=\left(a_{x-p} \times P_{x}+a_{x-n} \times N_{x}\right) \times \text { Random } \times M_{x} \times F_{x}
\end{gathered}
$$

In Formulas (7)-(8), Random is a variable used to represent the unpredictable effects of all other social or economic changes that haven't been included in this 
research yet; and $\gamma$ is a random number drawn from $(0,1)$, while $\partial$ is the controlling parameter whose value will range from 1 to 10 (Yali, 2013); $U_{x}$ is the suitability value for land use type $x$ after synthesizing all influence factors; and both $\alpha_{x-p}$ as well as $\alpha_{x-n}$ are the weight coefficients that stand for environment attributes and neighboring land respectively, and the sum of these two parameter values will always be equal to 1 .

3) Submitting the land development applications

As people usually follow the principle of utility maximization to make their decisions on land development projects (An, 2012; Benenson, 1998; Huang et al., 2014; Xia, 2003), the developer agents in this model would also use the similar method to determine which land parcel to bid. Therefore, after finishing the evaluation work of all potential choices, the developer agents would arrange them in a pecking order from top to bottom, according to different suitability values; and then choose one with the highest score as target land parcel, for which they will submit the development applications to the government agent.

4) Finishing the land transition job

If those development requests have been approved by the government agent after a series of calculation and comparison procedures, they would mark the qualified land parcels and change their attribute value from 0 to 1 , in which 1 is representing "allowed to build" and 0 is "not allowed to build". After that, the developer agents would identify those transition targets all at once by simply choosing land parcels with attribute value of 1 , and convert their property settings into the same status as the urban land use type that developer agents stand for.

5) Updating model environment

Before continue next round experiment, the developer agents need to calculate the difference between expected total area and existing lands to check whether their expansion tasks have been completed. If not, they have to eliminate all the calculation or decision marks from the model, and reevaluate the suitability value for land parcels according to its current surroundings so that they could finish the rest of development job based on the timely as well as effective information. But if the answer is yes, developer agents would jump into the next round simulation procedure after they have updated the attribute values for the entire modeling environment.

\subsubsection{Government Agent}

Since the simulation research has added the analysis function of urban renewal into the modeling procedures, the government agent not only needs to make judgments about different kinds of land development applications in urban expansion stage, but also takes on the responsibility of choosing suitable land targets for industrial renovation activities. Therefore, the government agent's simulation tasks in this model could be divided into two separate parts: assessing land development requests and governing industrial renewal process. 


\subsubsection{Assessing land Development Requests}

Similar to the land evaluation activities of developer agents, when government agent makes decisions about whether to approve the development request or not, it would also follow the principle of utility maximization to set up its simulation behavior rules (An, 2012; Honghui, 2011; José \& Lucien, 1993; Xia, 2003). As a result, government agent would firstly calculate the probability to approve for all development requests that have been submitted, and then choose one of them with the highest scores as a winner for this land competition (Hui \& Bao, 2013; Xia, 2003) and make final judgments based on the comparison result between competition winner and original land use type. Specific details about this decision-making process can be seen in Figure 4 and following paragraphs.

1) Probability Evaluation

When calculating the development probability for all submitted requests, government agent would follow the descriptions of Formulas (9)-(13) to evaluate their performances from three different aspects, which include environment attributes, neighboring land and urban planning (Haase et al., 2012; Yali, 2013). After that, it would combine their evaluation results together to calculate the original probability for approval, as shown in Formulas (14)-(15); and use the

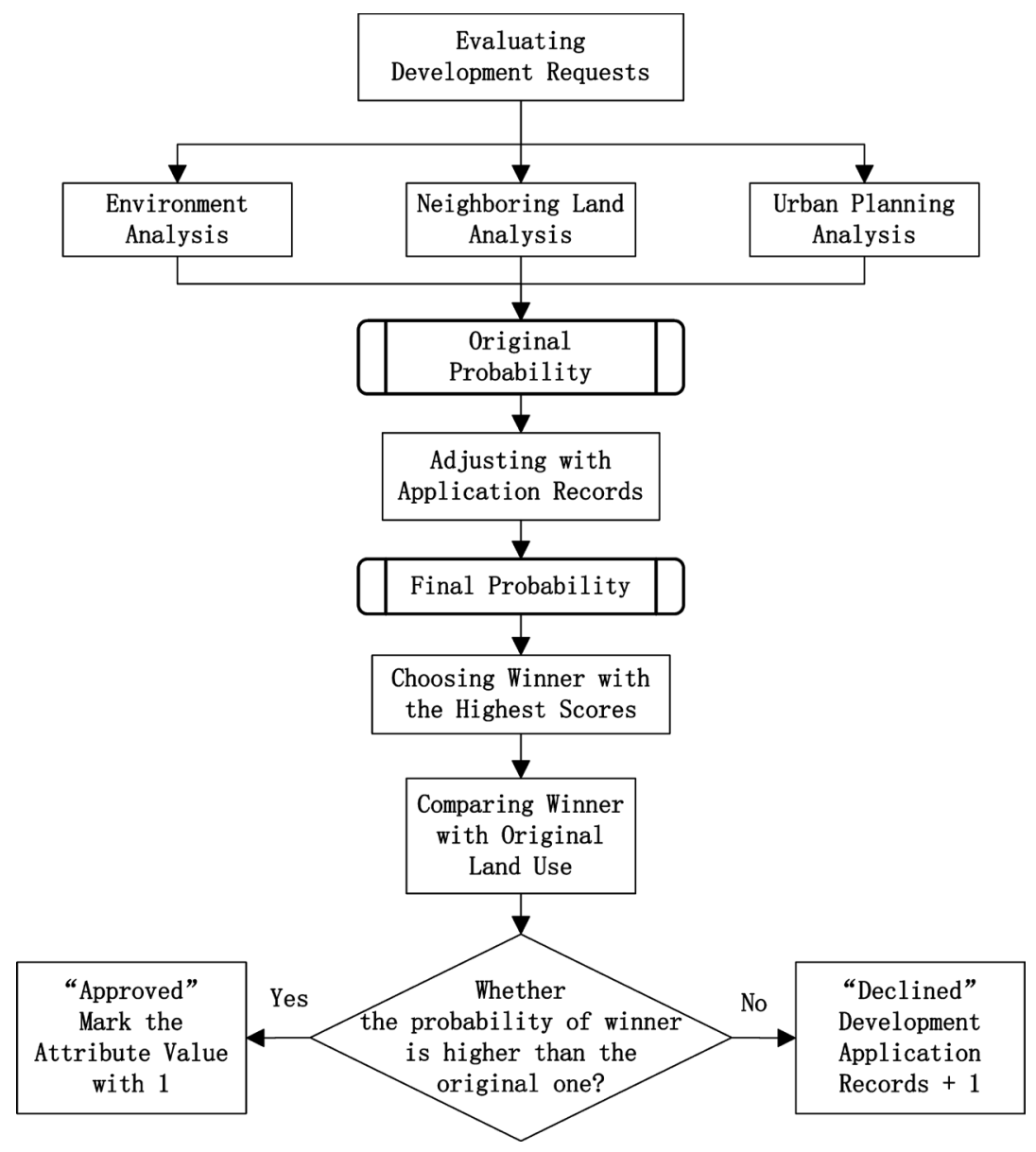

Figure 4. The flow chart of land development requests assessing process. 
accumulated application records to make some adjustments (Xia, 2003; Yali, 2013), which can be seen as a reflection of mutual effects between government and developer agents. And it is also worth noting that in the real world, planning schemes can make great influences on the decision-making process of government administrations, and sometimes it is even decisive for the whole construction project, like the environmental protection laws; so it is necessary for us to include the analysis function of urban planning into the government evaluation process.

a) Environment Analysis

$$
\begin{gathered}
S_{x x}^{\prime \prime}=S_{x x} / S_{x x-\text { mean }} \\
Y_{x}=w_{x-\text {-lev }} S_{\text {elev }}^{\prime \prime}+w_{x-\text { slope }} S_{\text {slope }}^{\prime \prime}+w_{x-\text { green }} S_{\text {green }}^{\prime \prime}+\cdots+w_{x-m f} S_{m f}^{\prime \prime}+\varepsilon_{x} \\
Q_{x}=Y_{x} /\left(Y_{0}+Y_{r}+Y_{c}+Y_{i}\right)
\end{gathered}
$$

In Formulas (9)-(11), $S_{x x}^{\prime \prime}$ is the non-dimensionalized value of different environment attributes; and $x$ represents the land use type of developer agent, which includes three kinds of choices: $r$ (residential), $i$ (industrial) and $c$ (commercial); as to $Y_{x}$, it is the synthesized analysis result of all attribute factors, which is calculated by multinomial logistic regression. $\omega_{x \text {-elev }}, \omega_{x \text {-slope }}, \cdots$ are the weight coefficients for different attribute factors; and $\varepsilon_{x}$ is the constant term of multinomial logistic regression. Due to the original land use type of target parcel has been chosen as a reference during the analysis process, its regression calculation result $\left(Y_{0}\right)$ will always keep the same value of 1 . And the development probability in environment evaluation stage for each construction requests $\left(Q_{x}\right)$, is eventually determined by the ratio that its regression result contributes to the sum of all development choices.

b) Neighboring Land Analysis

$$
N_{g-x}=\left(\sum_{x-g m}(\text { Landuse }=“ x ”)\right) / n
$$

In Formula (12), $N_{g-x}$ represents the evaluation results of land use type $x$ within a limited area around the target parcel; $x$ - $g m$ is the search radius that government agent uses to limit the scope of assessment; and $n$ is the total area of land parcels within the range of $x$-gm, while $\sum($ Landuse $=$ " $x$ ") represents the total area of land parcels with the particular land use type of $x$.

c) Urban Planning Analysis

$$
\operatorname{Plan}_{x}= \begin{cases}1 & \left(\text { If } L_{x}=L_{0}\right) \\ 0 & \left(\text { If } L_{x} \neq L_{0}\right)\end{cases}
$$

In Formula (13), $\operatorname{Plan}_{X}$ represents the comparison results between proposed land use type and land use type in planning schemes; $L_{x}$ is the land use code set by the development requests, and $L_{0}$ is the land use code scheduled by the urban planning scheme of 2050.

d) Comprehensive Calculation

$$
T_{x}=\left(a_{x-Q} \times Q_{x}+a_{x-\text { Plan }} \times \operatorname{Plan}_{x}\right) \times\left(1+N_{g-x}\right)+\Delta t \times n_{x}
$$




$$
T_{0}=Q_{0}=Y_{0} /\left(Y_{0}+Y_{r}+Y_{i}+Y_{c}\right)
$$

In Formulas (14)-(15), $T_{X}$ is the synthesized evaluation result for development requests of land use type $x$, while $T_{0}$ represents the probability values of the original land use type; both $\alpha_{x-Q}$ and $\alpha_{x-\text { Plan }}$ are the weight coefficients that stand for environment attributes and urban planning respectively, and the sum of these two parameter values will be always equal to $1 ; n_{x}$ is the accumulated number that developer agents of land use type $x$ used to apply for, and $\Delta t$ is representing the unit impact that each application could bring to the probability calculation process.

2) Development Decision-Making

After having calculated the probability to approve for each development applications, government agent has to make judgments based on the comparison results among different requests, and choose one with the highest probability values as the final winner of this land development competition. But due to the fact that the original land use type of target parcel is also one of the possible choices in this decision-making process, so after government agent has decided the development competition winner, it also need to compare its probability values with the original land use type. Only if the winner has a relatively higher scores can government agent approve its transition requests and mark the parcel's attribute value with 1 , which means "allowed to build"; otherwise, it will decline requests and keep the target parcel remain in the same land use type as it used to be.

\subsubsection{Governing Industrial Renewal Process}

Although there are many kinds of industrial renovation activities, like updating, relocation and so on, this research program will only focus on simulating the type of industrial facilities being converted into residential or commercial land. Therefore, as shown in Figure 5, after government agent has calculated the transition task for urban renewal procedures through linear regression formula, it would evaluate the renewal probabilities for all potential industrial lands from three different aspects (environment/neighboring land/ urban planning), and choose one with the highest scores as its final target for industrial renovation activities. After that, it would invite both residential and commercial developer agents to participate into the following land transition process, and use similar evaluation standards as well as decision-making mechanisms like it does in the "development request assessing" stage to help decide which land use type that the target industrial land would be converted to in the following transition process.

Considering that the evaluation procedures which government agent used to calculate the transition probabilities for industrial land are very similar to those in Section 3.3.2.1, and the major difference between them is their parameter settings; so for the purpose of avoiding repeated illustrations, all calculation details about this industrial renewal process will be represented in Appendix 3. 


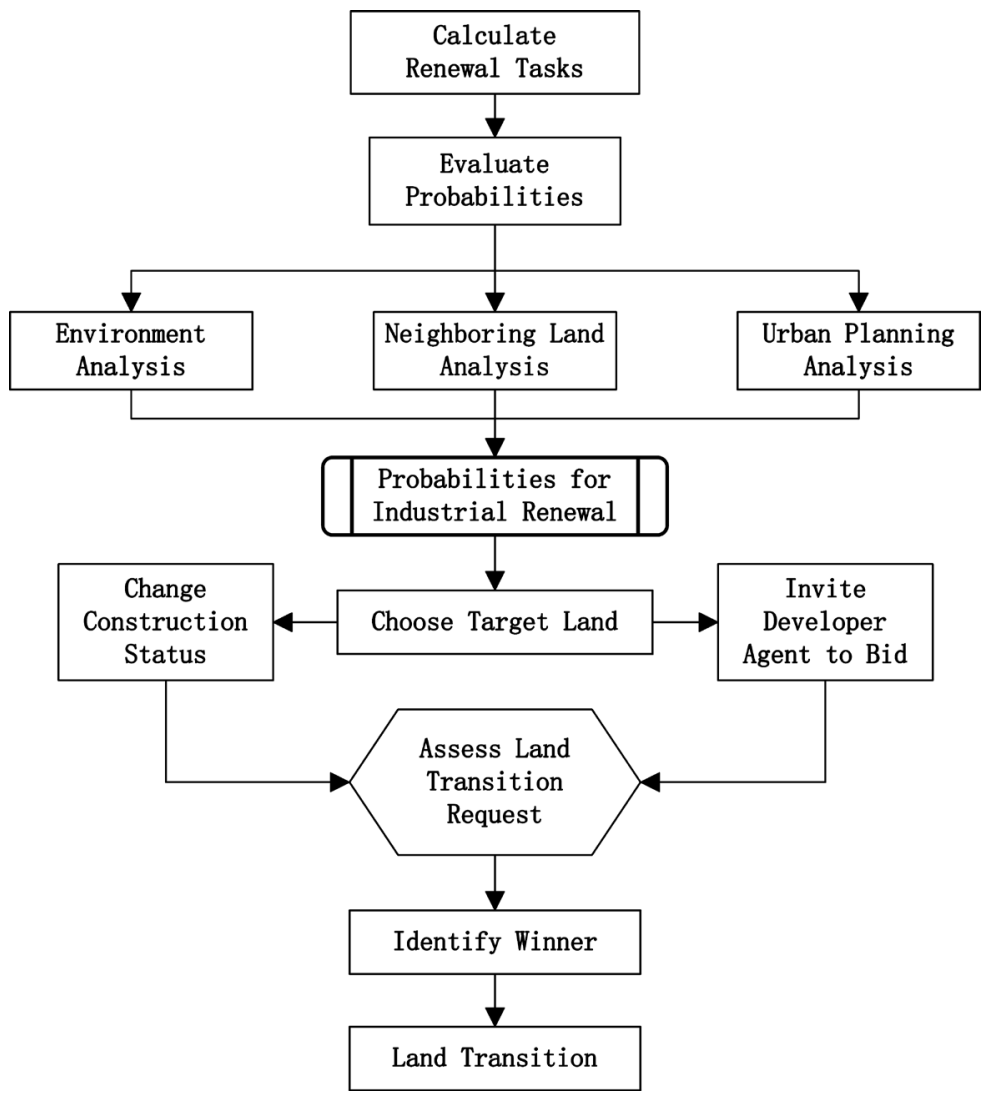

Figure 5. The flow chart of industrial renewal governing process.

\section{Verification Research}

Before applying the simulation model into other research activities, for example predicting future land development or evaluating possible effects for urban land policies, it is necessary for us to verify that whether its analysis results are consistent with the reality (Windrum et al., 2007), so that the accuracy of this simulation model can be ensured. Therefore, in the following sections, this paper will conduct a verification research based on the land use data of San Diego in 2008, and use the model to simulate the land development process from 2008 to $2014^{1}$. After that, it will adopt both point-by-point analysis and geometrical calculation methods (Windrum et al., 2007; Xia, 2003) to compare its simulation layout with the actual urban space pattern of 2014, and make judgments about the modeling accuracy through their similarity comparison results.

\subsection{Point-by-Point Analysis}

As shown in Formula (16), the analysis mechanism for point-by-point calculation method is to overlay the simulation layout with actual land use map together, and calculate the ratio between converted lands which have the same land use type as in reference map, and all land parcels that used to participate in this ur-

${ }^{1}$ GIS data derived, modified, reduced, and/or processed from SanGIS downloadable data https://www.sangis.org/ Copyright SanGIS 2009. 
ban development process. From the statistics shown in Table 1 we can see that, both the simulation accuracy for urban expansion and urban renewal activities have reached beyond the standard of $70 \%$, so it is safe for us to conclude that the modeling procedure about agent's location preferences and its behavior rules have captured the main characteristics of real world; and this simulation model is capable of predicting the general development trend for urban land system with high accuracy.

$$
\operatorname{Accuracy}_{x}=\left(M_{x} / N_{x}\right) \times 100 \%
$$

In Formula (16), Accuracy $_{x}$ is representing the point-by-point comparison results for different kinds of land development activities, which include urban expansion $(x=k)$ and urban renewal $(x=g) ; M_{x}$ is the total area of land parcels that have been converted into the correct land use type; and $N_{x}$ is the total area of land parcels that used to participate in this land transition process.

\subsection{Geometrical Calculation}

Although there are many kinds of geometrical analysis methods, after referring to previous studies, this paper decides to compare the differences between simulation layout and actual land use pattern through evaluating three typical space indexes, which include self-autocorrelation (Moran's I), compactness (CR) and fragmentation (FD) (BeiBei et al., 2013; Xu et al., 2003; Yu et al., 2015). As indicated by their names, the research mechanisms for those space indexes are calculating the intensity of space correlation among different land use types, evaluating the concentration degrees for all land parcels and measuring the complexity of boundary shape in build-up areas. Specific details about these calculation processes can be seen in Appendix 4.

According to the statistics shown in Table 2, there are only minor differences between simulation layout and actual urban space pattern on their index values. So it is reasonable for us to conclude that the simulated urban space structure shares a lot of similarity with the real world, and we can use it to conduct the following prediction research. Besides that, after comparing those index values with other cities' measurements, we could also discover that the San Diego has a

Table 1. The point-by-point analysis results for urban development activities.

\begin{tabular}{lll}
\hline Development Activities & Urban Expansion & Urban Renewal \\
\hline Accuracy & $71 \%$ & $77 \%$ \\
\hline
\end{tabular}

Table 2. The geometrical analysis results for urban space structure (2014).

\begin{tabular}{ccc}
\hline Space Index & Simulation Layout of 2014 & Actual Space Pattern of 2014 \\
\hline Self-autocorrelation (Moran's I) & 0.7559 & 0.7519 \\
Compactness (CR) & 0.0485 & 0.0487 \\
Fragmentation (FD) & 1.3596 & 1.3486 \\
\hline
\end{tabular}


relatively segregated as well as dispersed urban space pattern, and its city outlines is unusually complex and broken due to the disordered distribution of urban land parcels. Therefore, this geometrical analysis not only proves the effectiveness of proposed model in representing the main features of urban land development in real world, but also expresses a fact that there are many drawbacks in current urban space structure, for example the inefficiency of land resource management, the unbalanced allocations of public services and so on. All of these could bring harm to the sustainable development of urban land system in San Diego, so there is urgent need for us to optimize the existing land management policies and provide the city with a more intensive as well as effective development mode in the future.

\section{Scenarios Comparison}

Considering that suitable land management could play a vital role in optimizing urban space structure and facilitating sustainable development activities, this paper will follow the experiences of real world to set up three different types of administration scenarios, which include natural development, environment protection and economy dominated scenes, and use them to conduct simulation research about the future land development in San Diego from 2014 to 2050. After that, in order to get a more comprehensive understanding about the influences that each land policy would bring to the urban space structure, this paper will adopt both visual observation and geometrical calculation methods to analyze the simulation layouts from various perspectives, and draw reasonable conclusions about their practical application values through the comparison results among different administration scenarios.

\subsection{Scenarios Setup}

\subsubsection{Natural Development Scenario}

The main task for natural development research is to set up a baseline model for the following comprehensive analysis and to analyze how the urban space structure of San Diego would evolve in the future (2014-2050) if it is still under the same administration environment like it used to be. Therefore, all function flows and procedure settings in this scenario will keep unchanged when the simulation research is carried out. Specific details about agent's behavior rules and their evaluation standards can be seen in Section 3, and they will not be stated here repeatedly.

\subsubsection{Environment Protection Scenario}

As indicated by its name, the importance of environment protection is prior to the urban development activities in this simulation scenario, which means how to prevent urban expansions from invading other landscape or agriculture lands would become the core target while setting up agents' behavior rules. So, in order to strengthen the supervision efforts and to reduce the danger that domestic 
pollutions spread from outside of the protected areas, government agent would expand the scope of construction limited zones to better protect the environment. To be more specific, not only those ordinary landscape or agriculture lands would be set as construction prohibited zones, but also areas around them are going to receive different kinds of regulations so that developer agents could follow the order of "from far and near" to arrange their development activities. Therefore, in this scenario, government agent would evaluate the potential negative impacts on environment protection based on its space distance to the nearest protection zones, and adjust its development probability values accordingly. More details about this modified calculation process can be seen in Appendix 5.

\subsubsection{Economy Dominated Scenario}

Similar to the urban growth pattern in developing countries, there are almost no restrictions for land development activities in this simulation scenario during the urban expansion stage. As a result, government agent would eliminate all construction-prohibited marks from the virtual environment, and developer agents here can choose any target parcel they want, except military jurisdictions, to carry out land transition activities. Except that, in order to make the developing process more convenient, this scenario has also simplified the evaluation as well as decision-making procedures for the government agent so that it doesn't have to compare the probability values between competition winner and original land use type during the development assessing process, and all construction applications would automatically receive the permission to build if there is no other developer agent to compete for the land. Specific details about this simplified calculation process can be seen in Appendix 6.

\subsection{Comprehensive Analysis}

\subsubsection{Observation for General Layout}

Figure 6 is a brief demonstration of land development trends in three different simulation scenarios. As it shows in the picture, both natural development and environment protection scenarios have similar urban space layouts for all three types of land development activities, in which most of the newly-added residential lands are prefer to locate in the northern part of the city and close to the area with high quality landscape resources, while the industrial construction projects are mainly concentrating in the border areas of north San Diego. As to those newly-developed commercial lands, they have a relatively scattered distribution pattern, and except for the allocations in traditional city center, there are also some construction activities being carried out in either north or south part of the city. But contrary to that, the urban space structure in economy dominated scene bears little similarity with previous two simulation scenarios, in which not only residential and commercial lands have increased the density of distribution in central areas, but also the extent that industrial lands concentrating in the southern part of San Diego has been greatly enhanced. 


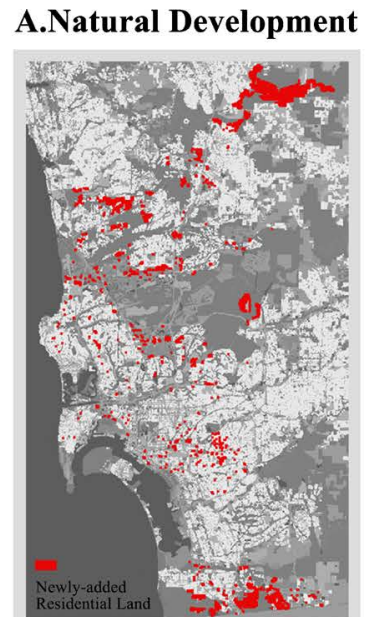

A(1).Residential Land

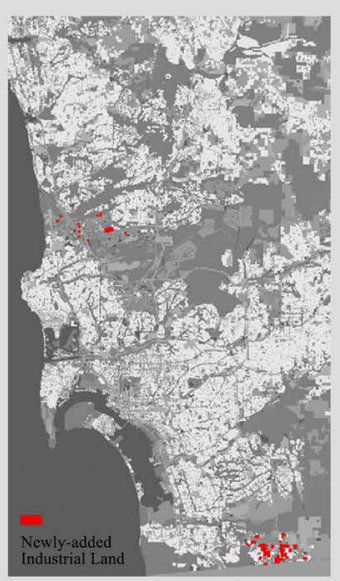

A(2).Idustrial Land

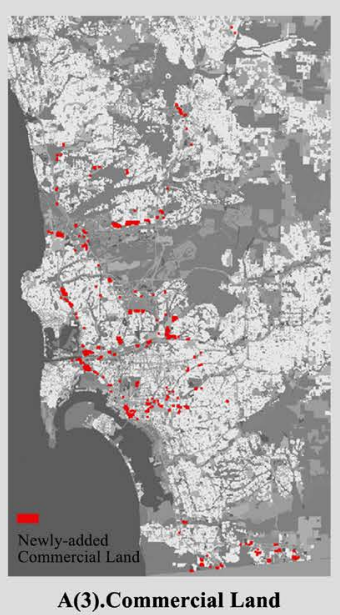

\section{B.Environment Protection}

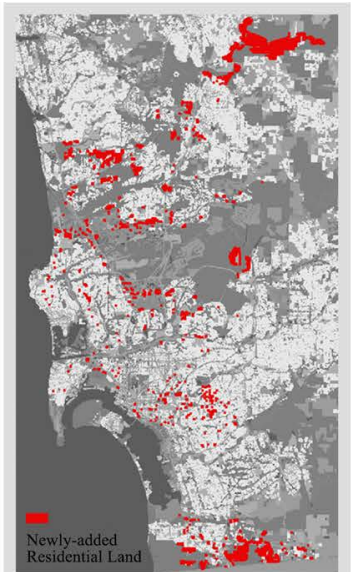

B(1).Residential Land

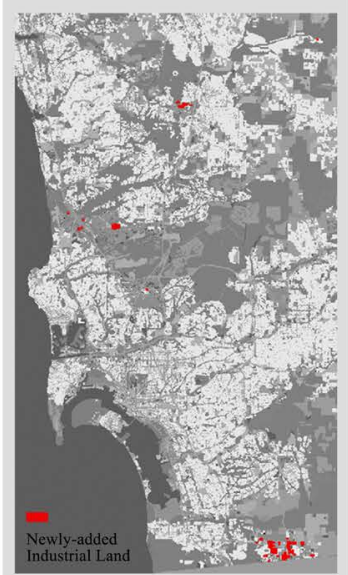

B(2).Industrial Land

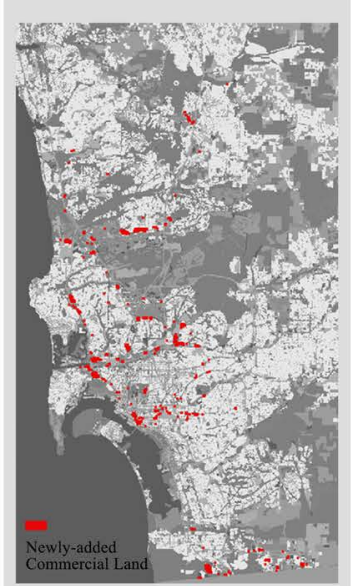

B(3).Commercial Land

\section{C.Economy Dominated}

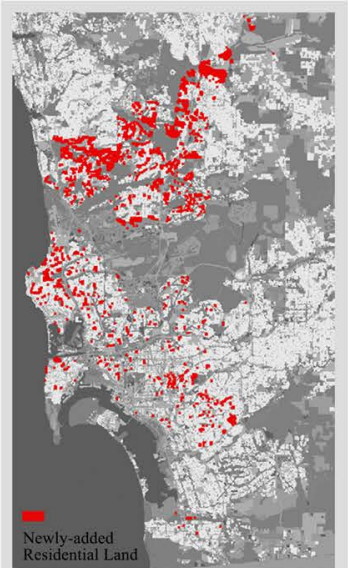

C(1).Residential Land

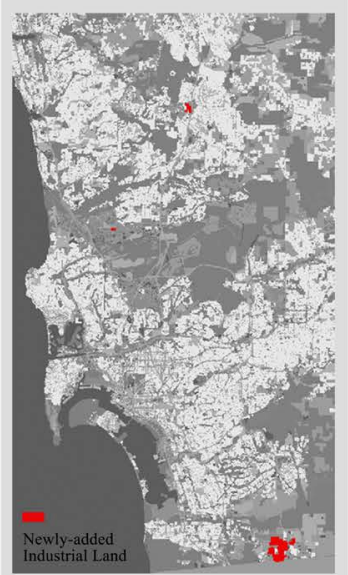

C(2).Industrial Land

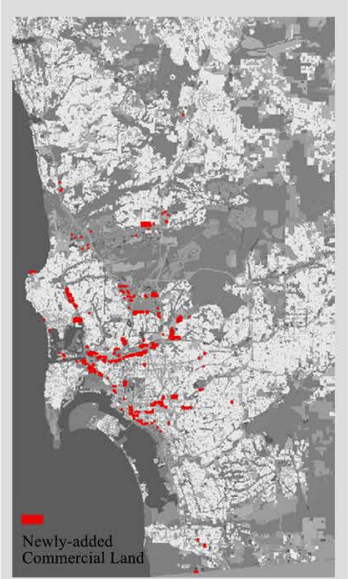

C(3).Commercial Land

Figure 6. General Layouts for different administration scenarios.

The reason for natural development (ND) and environment protection (EP) scenarios share high similarity on the general layouts, lies in the fact that there is only limited land resources left in San Diego due to the establishments of various protection zones and military facilities. So, even if the government agent in EP 
plans to guide those development activities away from the protection zones, without enough alternative spaces for the reallocations, developer agents would soon be forced back to the original place to carry out construction projects, which eventually lead to an urban space pattern similar to the baseline model (ND). But when government agent eliminates all restriction rules in economy dominated scenario (ED), the possible areas for urban land development would be greatly expanded. Therefore, developer agents can fully comply with their instinctive preferences as well as utility-maximization principles to set up the construction projects on the ideal land parcels, which would further facilitate the concentrated behaviors in both regional center and urban functional groups with the same land use type, just like the industrial agglomeration phenomenon used to show us before.

\subsubsection{Calculation for Geometrical Index}

According to the evaluation results in Table 3, all three types of simulation scenarios have gained relatively high autocorrelation index values, which indicates that no matter what kind of land policies has been applied, the developer agents would show a strong tendency of being close to the areas with same land use type during its site selection process. Therefore, after eliminating the restrictions on urban land development, more construction projects would be carried out near the area of the same land use type, so the autocorrelation index in economy dominated scenario (ED) is a little higher than other two simulation layouts due to its enhancement on the concentration behaviors. Besides that, both the calculation results of compactness and fragmentation index also tell us a fact that the urban space pattern in all three types of simulation scenarios have displayed the obvious feature of dispersion as well as expansion. And compared with other two simulation scenarios, the urban space structure in ED is even more dispersed as well as disorganized for the developer agents can choose any scattered land parcels they want after the development restrictions have been eliminated. Therefore, those randomly placed construction projects not only reduce the land development efficiency significantly, but also make the general layout of urban environment more complex and fragmental.

\subsection{Strategy Optimization}

From above analysis, we may conclude that simply expanding or reducing the

Table 3. The geometrical analysis results for three alternative administration scenarios (2050).

\begin{tabular}{cccc}
\hline Simulation Scenarios & $\begin{array}{c}\text { Natural } \\
\text { Development }\end{array}$ & $\begin{array}{c}\text { Environment } \\
\text { Protection }\end{array}$ & $\begin{array}{c}\text { Economy } \\
\text { Dominated }\end{array}$ \\
\hline Self-autocorrelation (Moran's I) & 0.723966 & 0.730019 & 0.745743 \\
Compactness (CR) & 0.059811 & 0.059871 & 0.051914 \\
Fragmentation (FD) & 1.327121 & 1.325614 & 1.346372 \\
\hline
\end{tabular}


scope of construction-limited areas, as shown in environment protection and economy dominated scenarios, cannot fundamentally solve the problems of segregated functional layout, dispersed space structure and inefficient development activities. Therefore, it is necessary for us to combine other optimization measures to draw up a new and effective land management policy based on the consideration of current environment conditions and urban development needs, so that we could facilitate the sustainable construction activities in San Diego for future land development.

\subsubsection{Suggestions for Policy Optimization}

As illustrated in the comprehensive plan of 2050 (Regional comprehensive plan, 2015) and smart growth principles (Smart growth design guidelines, 2009), in order to improve the land development efficiency and to optimize urban space structures, San Diego government not only needs to introduce policies that could encourage construction activities being carried out around regional center or arterial streets, but also should increase the frequency of mixed land development in community center so as to enlarge the scope of public services while reducing the travel demands of residents to a large extent. In additional to that, for the purpose of protecting environment and boosting industrial productions, government also needs to guide those industrial development activities into the middle part of the city, where there is a lot of flat lands suitable for large-scale construction projects and a bunch of research facilities that could provide an unfailing supply of innovative technologies. As to easing the tensions between limited land resources and enormous development needs, one of the most effective measures for land management is to launch all kinds of urban renovation projects among built up areas, so that parts of construction plans could be realized through converting less efficient developed lands. And by attracting developers to gather around build up areas, those renovation projects could also play a important role in restraining the disordered expansion trend for urban development.

\subsubsection{Evaluation of Policy Implementation}

In order to verify the specific effects of those optimization methods proposed above, this paper will follow their descriptions to set up a new administration scenario and use it to conduct the same simulation research of predicting future land development from 2014 to 2050. After that, both visual observation and geometrical calculation methods will be adopted to analyze the characteristics of the simulation layout so we could evaluate their performances through the comparison results with other three scenarios mentioned in Section 5.1.

Generally speaking, to represent those optimization measures in the land development process, the research model have to make some modifications on its simulation procedures, which include: 1) adding the analysis function of proximity to the regional center or arterial streets for developer agents, and using them to adjust the suitability calculation results during the site selection process; 
2) increasing the variety of urban renovation activities, and including other less efficient land use types, like parking or storage, as potential transition sources for residential, industrial and commercial development; 3) eliminating or reducing the limits of separation distance among different land use types so as to facilitate the mixed land development by drawing them closer; 4) taking those ordinary landscape or agriculture lands, which are not defined as key protection zones by law, as potential urban expansion sources, and setting up grading system for them while calculating the construction suitability values; 5) identifying certain areas in the middle part of the city as an attraction for industrial development, and marking the land parcels around them with different attraction values according to their space distance away from the core target.

Figure 7 is the general layouts of different land use types in optimized scenario. Compared to the urban space patterns in Figure 6, we can see that not only the development density of residential land around regional center and arterial streets has been increased to a certain extent; but also some of industrial construction projects are being transferred to the middle part of the city where the industrial cluster is located; and due to the guidance effect of south-north arterial roads, more commercial development activities have been spread out of the city center and reached the remote areas, which eventually leads to a relatively even distribution of commercial services. Furthermore, after calculating the differences between Table 3 and Table 4, we could also discover that both the index values of auto-correlation and fragmentation have been reduced in different degree, while the compactness of urban space layout is being raised slightly.

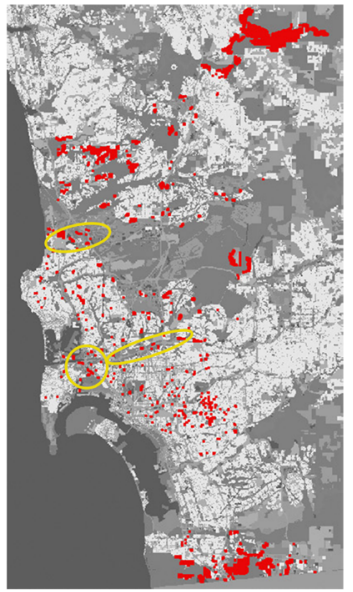

A.Residential Land Newly-added Land

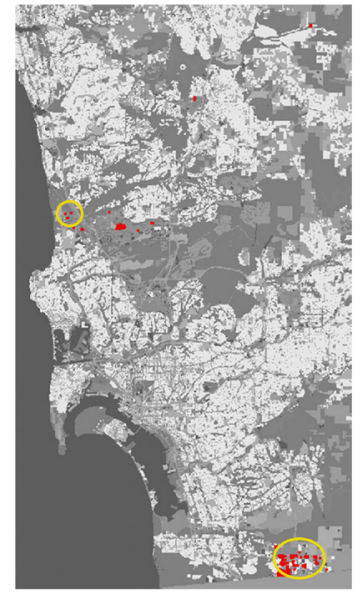

B.Industrial Land

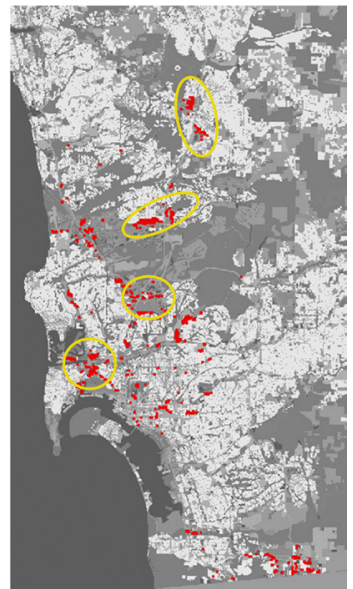

C.Commercial Land

Figure 7. The general layouts for optimized simulation scenario.

Table 4. The geometrical analysis results for the optimized administration scenario.

\begin{tabular}{cccc}
\hline Space Index & $\begin{array}{c}\text { Self-autocorrelation } \\
\text { (Moran's I) }\end{array}$ & $\begin{array}{c}\text { Compactness } \\
\text { (CR) }\end{array}$ & $\begin{array}{c}\text { Fragmentation } \\
\text { (FD) }\end{array}$ \\
\hline Evaluation Results & 0.723008 & 0.060503 & 1.32008 \\
\hline
\end{tabular}


Therefore, based on the analysis results of visual observation and geometrical calculation, it is reasonable for us to conclude that the optimized land policies can not only facilitate the mixed land development activities and reduce the segregation level among different land use types, but also increase the attractiveness of regional centers and make the distribution of construction projects even more concentrated so that those disordered expansion activities around the urban fringe could be effectively restrained.

\section{Conclusion}

In this paper, we have set up a simulation model for urban land development in San Diego by using multi-agent simulation (MAS) software, and conducted research to study its functional mechanism as well as future development trend through the interactive activities among four types of agents and their surrounding environment. After having determined the agents' behavior rules and parameter settings via logistic regression, entropy calculation and other statistic analysis methods, we carried out a verification research to simulate the land development process from 2008 to 2014, and examined its consistency with the reality by making use of both point-by-point and geometrical calculation methods. Later, we also designed three types of administration scenarios following the land management experiences in real world, and compared their differences from two separate perspectives: visual observation and geometrical calculation, which lead to a conclusion that simply modifying the scope of constructionrestricted areas cannot help to solve the existing problems of urban development. Therefore, in order to effectively overcome the current drawbacks of urban space layout, like segregation and dispersion, and to facilitate the sustainable development activities in San Diego, we proposed several possible ways for policy optimization based on the suggestions of comprehensive plan in 2050 and smart growth principles, and proved their effectiveness through the comparison research between optimized scenario and other three administration policies mentioned above.

Although this research model has obtained plausible simulation results and made some achievements in both modeling structure and functional design, for example dividing the expansion activities into three different subclasses, adding the analysis function of urban renovations and so on; it still has some room for future improvement, in the consideration that there may be some shortcomings caused by the incomplete recognition on research subject or the limited capacity of simulation software. Therefore, in order to further increase the consistency between simulation layouts and urban space pattern in the real world, some measures could be taken to optimize the current modeling procedures (Filatova et al., 2013; Railsback \& Grimm, 2012; Runjiao et al., 2016), which include: 1) adding variety to both urban expansion and urban renovation activities; 2) integrating the knowledge of other subjects into the designing process of agent behavior rules, like urban economics, environmental psychology and so on; 3) us- 
ing neural network or other kinds of intelligent algorithms to improve the efficiency as well as the accuracy of agent's decision-making behaviors; 4) adjusting the unit of time into a finer scale so that more details can be added into the land development process, and agents can also have flexible time schedules for carrying out different types of construction projects accordingly.

In conclusion, the individual-based modeling methods for multi-agent simulation (MAS) research can not only help us to better understand those complex as well as dynamic interaction behaviors during the land development process, but also increase the accuracy of simulation results through the realistic design details. Therefore, compared to traditional "top-down" research models, MAS has great advantages in representing the internal operating mechanisms for urban complex system, and it is reasonable for us to use it as a major tool to conduct simulation research on land development in the future.

\section{Acknowledgements}

This research paper is supported by the National Natural Science Foundation of China (Grant No. 52008397). All the fees for both simulation software and data processing work are paid from this national foundation, and it will continue to support my future research project derived from this paper.

\section{Conflicts of Interest}

The author declares no conflicts of interest regarding the publication of this paper.

\section{References}

(2015). Regional Comprehensive Plan. http://www.sandag.org/?projectid=1\&fuseaction=projects.detail

(2009). Smart Growth Design Guidelines.

http://www.sandag.org/index.asp?classid=12\&projectid=344\&fuseaction=projects.detai 1

(2014). World Urbanization Prospects. https://esa.un.org/unpd/wup

An, L. (2012). Modeling Human Decisions in Coupled Human and Natural Systems: Review of Agent-Based Models. Ecological Modelling, 229, 25-36. https://doi.org/10.1016/j.ecolmodel.2011.07.010

Arsanjani, J. J., Helbich, M., \& Vaz, E. D. N. (2013). Spatiotemporal Simulation of Urban Growth Patterns Using Agent-Based Modeling: The Case of Tehran. Cities, 32, 33-42. https://doi.org/10.1016/j.cities.2013.01.005

Batty, M. (2005). Cities and Complexity: Understanding Cities with Cellular Automata, Agent-Based Models, and Fractals. Cambridge, MA: The MIT Press.

BeiBei, G., ZhongXiang, Y. U., XuHong, Y., XiaoBin, J., \& YinKang, Z. (2013). Urban Sprawl Research Based on GIS and Fractal Theory: A Case Study of Ma'anshan City, China. Resources and Environment in the Yangtze Basin, 22, 972-978.

Benenson, I. (1998). Multi-Agent Simulations of Residential Dynamics in the City. Com- 
puters Environment \& Urban Systems, 22, 25-42.

https://doi.org/10.1016/S0198-9715(98)00017-9

Crooks, A. (2006). Exploring Cities Using Agent-Based Models and GIS. Working Paper Series.

Ettema, D. (2011). A Multi-Agent Model of Urban Processes: Modelling Relocation Processes and Price Setting in Housing Markets. Computers, Environment and Urban Systems, 35, 1-11. https://doi.org/10.1016/j.compenvurbsys.2010.06.005

Filatova, T., Parker, D., \& Veen, A. V. D. (2009). Agent-Based Urban Land Markets: Agent's Pricing Behavior, Land Prices and Urban Land Use Change. Journal of Artificial Societies \& Social Simulation, 12, 3.

Filatova, T., Verburg, P. H., Parker, D. C., \& Stannard, C. A. (2013). Spatial Agent-Based Models for Socio-Ecological Systems: Challenges and Prospects. Environmental Modelling \& Software, 45, 1-7. https://doi.org/10.1016/j.envsoft.2013.03.017

Haase, D., Haase, A., Kabisch, N., Kabisch, S., \& Rink, D. (2012). Actors and Factors in Land-Use Simulation: The Challenge of Urban Shrinkage. Environmental Modelling \& Software, 35, 92-103. https://doi.org/10.1016/j.envsoft.2012.02.012

Heppenstall, A. J., Crooks, A. T., See, L. M., \& Batty, M. (2012). Agent-Based Models of Geographical Systems. Berlin: Springer. https://doi.org/10.1007/978-90-481-8927-4

Honghui Z. (2011). Urban Planning Spatial Decision-Making Model Based on Multi-Agent System and Its Application. Changsha: Central South University.

Huang, Q., Parker, D. C., Filatova, T., \& Sun, S. (2014). A Review of Urban Residential Choice Models Using Agent-Based Modeling. Environment \& Planning B Planning \& Design, 41, 661-689. https://doi.org/10.1068/b120043p

Hui, E. C. M., \& Bao, H. (2013). The Logic behind Conflicts in Land Acquisitions in Contemporary China: A Framework Based upon Game Theory. Land Use Policy, 30, 373-380. https://doi.org/10.1016/j.landusepol.2012.04.001

José, M. C. P., \& Lucien, D. (1993). A Multiple Criteria Decision-Making Approach to GIS-Based Land Suitability Evaluation. International Journal of Geographical Information Systems, 7, 407-424. https://doi.org/10.1080/02693799308901971

Magliocca, N., Safirova, E., Mcconnell, V., \& Walls, M. (2011). An Economic Agent-Based Model of Coupled Housing and Land Markets (Chalms). Computers Environment and Urban Systems, 35, 183-191. https://doi.org/10.1016/j.compenvurbsys.2011.01.002

Mansury, Y. (2015). Bottom-Up Computational Models of Urban Systems: In Search of Micro-Foundations. Computers Environment and Urban Systems, 54, 385-387. https://doi.org/10.1016/j.compenvurbsys.2015.10.006

Marks, R. (2006). Market Design Using Agent-Based Models. In Handbook of Computational Economics (Vol. 2, pp 1339-1380). Amsterdam: Elsevier. https://doi.org/10.1016/S1574-0021(05)02027-7

Matthews, R. B., Gilbert, N. G., Roach, A., Polhill, J. G., \& Gotts, N. M. (2007). Agent-Based Land-Use Models: A Review of Applications. Landscape Ecology, 22, 1447-1459. https://doi.org/10.1007/s10980-007-9135-1

Parker, D. C., \& Filatova, T. (2008). A Conceptual Design for a Bilateral Agent-Based Land Market with Heterogeneous Economic Agents. Computers Environment \& Urban Systems, 32, 454-463. https://doi.org/10.1016/j.compenvurbsys.2008.09.012

Parker, D. C., Manson, S. M., Janssen, M. A., Hoffmann, M. J., \& Deadman, P. (2003). Multi-Agent Systems for the Simulation of Land-Use and Land-Cover Change: A Review. Annals of the Association of American Geographers, 93, 314-337. 
https://doi.org/10.1111/1467-8306.9302004

Railsback, S. F., \& Grimm, V. (2012). Agent-Based and Individual-Based Modeling: A Practical Introduction. Princeton, NJ: Princeton University Press.

Robinson, D. T., Murray-Rust, D., Rieser, V., Milicic, V., \& Rounsevell, M. (2012). Modelling the Impacts of Land System Dynamics on Human Well-Being: Using an Agent-Based Approach to Cope with Data Limitations in Koper, Slovenia. Computers Environment \& Urban Systems, 36, 164-176. https://doi.org/10.1016/j.compenvurbsys.2011.10.002

Runjiao L., Difei J., \& Lei S. (2016). Literature Review on Agent-Based Modeling in Urban Planning. City Planning Review, 40, 105-112.

Sun, S., Parker, D. C., Huang, Q., Filatova, T., \& Brown, D. G. (2014). Market Impacts on Land-USE Change: An Agent-Based Experiment. Annals of the American Association of Geographers, 104, 460-484. https://doi.org/10.1080/00045608.2014.892338

Ronghui, T., Yaolin, L., Kehao, Z., Limin, J., \&Wei, T. (2015). A Game-Theory Based Agent-Cellular Model for Use in Urban Growth Simulation: A Case Study of the Rapidly Urbanizing Wuhan Area of Central China. Computers Environment and Urban Systems, 49, 15-29. https://doi.org/10.1016/j.compenvurbsys.2014.09.001

Verburg, P. H. (2006). Simulating Feedbacks in Land Use and Land Cover Change Models. Landscape Ecology, 21, 1171-1183. https://doi.org/10.1007/s10980-006-0029-4

Windrum, P., Fagiolo, G., \& Moneta, A. (2007). Empirical Validation of Agent-Based Models: Alternatives and Prospects. Journal of Artificial Societies \& Social Simulation, 10,8 .

Xia L. (2003). Geographical Simulation System: Automata Cellular and Multi-Agent System. Beijing: Science Press.

Xu, J., Fang, C., \& Yue, W. (2003). An Analysis of the Mosaic Structure of Regional Landscape Using GIS and Remote Sensing. Acta Ecologica Sinica, 23, 365-375.

Yali L. (2013). Research on Expansion of Urban Construction Land and Carbon Emissions: A Case Study of Urban Area in Zhengzhou. Kaifeng: Henan University.

Yu, S., Ting, L., Yao, T., Weiping, Z., \& Wei, T. (2015). Quantitative Analyses of Changes in Urban Spatial Morphology under Rapid Urbanization in China. Ecological Science, $34,122-126$.

Zhuge, C., Shao, C., Gao, J., Dong, C., \& Zhang, H. (2016). Agent-Based Joint Model of Residential Location Choice and Real Estate Price for Land Use and Transport Model. Computers, Environment and Urban Systems, 57, 93-105.

https://doi.org/10.1016/j.compenvurbsys.2016.02.001 


\section{Appendix 1}

$$
S_{x x}^{\prime}= \begin{cases}\left(\left(S_{x x-\max }-S_{x x}\right)+\left(\left|S_{x x-\min }\right|+1\right)\right) / S_{x x \text {-mean }} & \text { Negative } \\ \left(S_{x x}+\left(\left|S_{x x-\min }\right|+1\right)\right) / S_{x x-\text { mean }} & \text { Positive }\end{cases}
$$

In Formula (1), $x \boldsymbol{X}$ represents the code name of different environment attribute factors, and its specific definition as well as the effect directions on different urban expansion activities can be seen in the following category table (Table A1); $S_{x x}$ is the original data of environment attribute factors, while $S_{x x}^{\prime}$ is the data that has gone through multiple analysis procedures, which include normalization, reversion and positive-transition; $S_{x x-\max }, S_{x x \text {-min }}$ and $S_{x x \text {-mean }}$ are representing the maximum value, minimum value and mean value for every attribute factors respectively.

$$
\omega_{z h-x}=\left(\omega_{c c-x}+\omega_{s z-x}\right) / 2
$$

In Formula (2), $\omega_{z h-x}$ represents the comprehensive weight for different attribute factors; $\omega_{c c-x}$ is the analysis results of analytic hierarchy process, and $\omega_{s z-X}$ is the weight value calculated by entropy analysis method.

Table A1. The category list for environment attribute factors.

\begin{tabular}{ccccc}
\hline Code Name & Attribute Factors & $\begin{array}{c}\text { Effect on } \\
\text { Residential } \\
\text { Land }\end{array}$ & $\begin{array}{c}\text { Effect on } \\
\text { Industrial } \\
\text { Land }\end{array}$ & $\begin{array}{c}\text { Effect on } \\
\text { Commercial } \\
\text { Land }\end{array}$ \\
\hline$S_{\text {elev }}$ & Elevation & $\downarrow$ & $\downarrow$ & $\downarrow$ \\
$S_{\text {slope }}$ & Slope & $\downarrow$ & $\downarrow$ & $\downarrow$ \\
$S_{\text {green }}$ & Distance to Landscape & $\downarrow$ & $\uparrow$ & $\downarrow$ \\
$S_{\text {lake }}$ & Distance to Lake & $\downarrow$ & $\uparrow$ & $\downarrow$ \\
$S_{\text {sea }}$ & Distance to Ocean & $\downarrow$ & $\uparrow$ & $\downarrow$ \\
$S_{\text {rail }}$ & Distance to Railway & $\uparrow$ & $\downarrow$ & $\downarrow$ \\
$S_{\text {road }}$ & Distance to Road & $\downarrow$ & $\downarrow$ & $\downarrow$ \\
$S_{\text {harbor }}$ & Distance to Harbor & $\uparrow$ & $\downarrow$ & $\downarrow$ \\
$S_{g a}$ & Distance to General Airport & $\uparrow$ & $\downarrow$ & $\downarrow$ \\
$S_{\text {ca }}$ & Distance to Commercial Airport & $\uparrow$ & $\downarrow$ & $\uparrow$ \\
$S_{\text {center }}$ & Distance to Downtown & $\downarrow$ & $\uparrow$ & $\downarrow$ \\
$S_{p f}$ & Distance to Positive Facilities & $\downarrow$ & $\uparrow$ & $\downarrow$ \\
$S_{n f}$ & Distance to Negative Facilities & $\uparrow$ & $\uparrow$ & $\uparrow$ \\
$S_{m f}$ & Distance to Military Facilities & $\uparrow$ & $\uparrow$ & $\uparrow$ \\
\hline
\end{tabular}

Specification: “ $\downarrow$ "represents that the attribute factor will bring negative effect to the suitability evaluation process, so the lower the data values is, the higher the calculation result will get; " $\uparrow$ " represents that the attribute factor will bring positive effect to the suitability evaluation process, so the higher the data values is, the higher the calculation result will get; 


\section{Appendix 2}

$$
\begin{aligned}
& R_{i}=\left\{\begin{array}{cc}
1 & \text { Safe to build (If } \left.D R_{i}>R F_{r}\right) \\
0 & \text { Not safe to buid (If } \left.D R_{i} \leq R F_{r}\right)
\end{array}\right.
\end{aligned}
$$

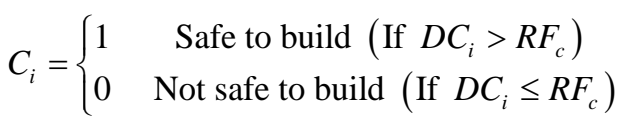

$$
\begin{aligned}
& F_{i}=\left\{\begin{array}{cc}
1 & \text { Allowed to build (If } \left.R_{i}=1 \text { and } C_{i}=1\right) \\
0 & \text { Not allowed to build (If } \left.R_{i}=0 \text { or } C_{i}=0\right)
\end{array}\right.
\end{aligned}
$$

In Formulas (1)-(3), $R_{i}$ and $C_{i}$ are representing the evaluation results of planning restrictions on industrial construction projects, and they are measured by the space distance to its nearest residential or commercial land respectively; similarly, $R F_{r}$ and $R F_{c}$ are standing for the minimum protection distance away from the residential or commercial land; and $D R_{i}$ is the space distance between industrial construction project and its nearest residential land, while $D C_{i}$ is the space distance to its nearest commercial land.

\section{Appendix 3}

$$
\begin{gathered}
Y_{z}=w_{z \text {-elev }} S_{\text {elev }}^{\prime \prime}+w_{z \text {-slope }} S_{\text {slope }}^{\prime \prime}+w_{z-g r e e n} S_{\text {green }}^{\prime \prime}+\cdots+w_{z-m f} S_{m f}^{\prime \prime}+\varepsilon_{z} \\
Q_{z}=Y_{z} /\left(Y_{0}+Y_{z}\right)
\end{gathered}
$$

In Formulas (1)-(2), $Y_{z}$ is the calculation results of binary logistic regression for urban renovation activities; $Y_{0}$ represents the evaluation results of original land use type, which is also chosen as the reference object during the calculation process; $Q_{z}$ is the renovation probability for industrial land evaluated from the perspective of natural environment; $S_{x x}^{\prime \prime}$ stands for the normalized data of different environment attribute factors, and its specific definition as well as calculation details can be seen in Appendix 1 and Section 3.3.2.2; $\omega_{z \text {-elev }}, \omega_{z \text {-slope }}, \cdots$ are the weight coefficients for different attribute factors, while $\mathcal{E}_{z}$ is the constant item of logistic regression formula.

$$
N Z_{g-x}=\left(\sum_{x-m}(\text { Landuse }=“ x ")\right) / n
$$

In Formula (3), $x$ represents the land use type of development applications, which includes three kinds of choices: $r$ (residential), $i$ (industrial) and $c$ (commercial); $N Z_{g x}$ is the evaluation results of land use type $x$ within a limited area around the target parcel; and $x-m$ is the search radius that government agent uses to limit the scope of assessment; $\mathrm{n}$ stands for the total area of land parcels within the range of $x$ - $m$, while $\sum($ Landuse $=$ " $x$ ") is representing the total area of land parcels with the particular land use type of $x$.

$$
R \text {-Plan }= \begin{cases}1 & \left(\text { If } L_{z h} \neq L_{0}\right) \\ 0 & \left(\text { If } L_{z h}=L_{0}\right)\end{cases}
$$

In Formula (4), $R$-Plan stands for the evaluation results of industrial renova- 
tion activities from the perspective of urban planning; $L_{z h}$ is the digital code of industrial land use type, while $L_{0}$ is representing the land use code set by the planning scheme of 2050 .

$$
R T=\left(a_{Q} \times Q_{z}+a_{R-\text { Plan }} \times R-\text { Plan }\right) \times\left(1+N Z_{g-r}\right) \times\left(1+N Z_{g-c}\right) \times\left(1-N Z_{g-i}\right)
$$

In Formula (5), $R T$ is the synthesized probability value of being carried out renovation activities; $Q_{x}$ and $R$-Plan are representing the evaluation results of natural environment and urban planning respectively, while $\alpha_{Q}$ and $\alpha_{R-P l a n}$ are standing for their weight coefficients during the calculation process, which means the sum of these two parameter values will always be equal to $1 ; N Z_{g-t}$, $N Z_{g-c}$ and $N Z_{g-i}$ are the neighboring land evaluation results on residential, commercial and industrial land respectively.

\section{Appendix 4}

$$
I=\left(n / \sum_{i=1}^{n} \sum_{j=1}^{n} W_{j i}\right) \times\left(\left(\sum_{i=1}^{n} \sum_{j=1}^{n} W_{i j}\left(x_{i}-\bar{x}\right)\left(x_{j}-\bar{x}\right)\right) /\left(\sum_{i=1}^{n}\left(x_{i}-\bar{x}\right)^{2}\right)\right)
$$

In Formula (1), $I$ is the calculation result of self-autocorrelation index; and $W_{i j}$ is the spatial contiguity weight matrix between parcel $i$ and parcel $j$, where 1 represents these two parcels are adjacent to each other and 0 is not; $\bar{X}$ stands for the average value among all land parcels, while $X_{i}$ and $X_{j}$ are representing the measurements of parcel $i$ and parcel $j$ respectively.

$$
C R=(2 \sqrt{\pi A}) / P
$$

In Formula (2), $C R$ is the compactness evaluation results of urban space layout; and $A$ is representing the total area of built-up region, while $P$ stands for the total length for all land parcels' outlines.

$$
\ln \left(A_{i}\right)=(2 / D) \times \ln \left(P_{i}\right)+C
$$

In Formula (3), $D$ represents the fractal dimension evaluation results of urban space layout; and $A_{i}$ is the area of land parcel $i$, while $P_{i}$ stands for its perimeter length; $C$ is the constant item of this calculation formula.

\section{Appendix 5}

$$
\begin{gathered}
P N_{x}= \begin{cases}3 & \left(\text { When } D_{p}>D_{x-2}\right) \\
2 & \left(\text { When } D_{x-2} \geq D_{p}>D_{x-1}\right) \\
1 & \left(\text { When } D_{x-1} \geq D_{p}\right)\end{cases} \\
P S_{x}= \begin{cases}0 & \left(\text { When } P N_{x}=3\right) \\
1 / 9 & \left(\text { When } P N_{x}=2\right) \\
1 / 3 & \left(\text { When } P N_{x}=1\right)\end{cases} \\
P T_{x}=T_{x} \times\left(1-P S_{x}\right)
\end{gathered}
$$

In Formulas (1)-(3), $x$ represents the land use type of development applica- 
tions, which includes three kinds of choices: $r$ (residential), $i$ (industrial) and $c$ (commercial); $P N_{x}$ is the assessment level of target land parcel on environment protection, and $P S_{x}$ is the specific scores that different assessment level will gain during the calculation process; $D_{p}$ stands for the space distance to its nearest protection zones, while $D_{x-1}$ and $D_{x-2}$ are representing the evaluation standards used to distinguish between different levels of environment protection zones; $T_{x}$ is original synthesized calculation results on development probability shown in Formula (14) of Section 3.3.2.1; and $P T_{X}$ is the probability value after being adjusted by the evaluation results of environment protections.

\section{Appendix 6}

$$
U_{x}=\left(a_{x-p} \times P_{x}+a_{x-n} \times N_{x}\right) \times \text { Random }
$$

In Formula (1), $U_{x}$ is the development suitability value for land use type $x, P_{x}$ and $N_{x}$ are representing the evaluation results of environment attribute factors and neighboring land respectively, as shown in Formulas (3)-(4) of Section 3.3.1, while $\alpha_{x-p}$ and $\alpha_{x-n}$ are standing for their weight coefficients during the calculation process; Random is a variable used to represent the unpredictable effects brought by all other social or economic changes that haven't been included in this simulation research yet, and its specific calculation details can be seen in Formula (7) of Section 3.3.1. 